\title{
Functional Alterations of Multidrug Resistance-Associated Proteins 2 and 5, and Breast Cancer Resistance Protein upon Snail-Induced Epithelial-Mesenchymal Transition in HCC827 Cells
}

\author{
Kentaro Yano, ${ }^{a, b}$ Itsuki Todokoro, ${ }^{a}$ Hiroki Kamioka, ${ }^{c}$ Takumi Tomono, ${ }^{c, d}$ and Takuo Ogihara ${ }^{*, a, c}$ \\ ${ }^{a}$ Laboratory of Biopharmaceutics, Department of Pharmacology, Takasaki University of Health and Welfare; 60 \\ Nakaorui-machi, Takasaki, Gunma 370-0033, Japan: ${ }^{b}$ Laboratory of Drug Metabolism and Pharmacokinetics, \\ Yokohama University of Pharmacy; 601 Matano-cho, Totsuka-ku, Yokohama 245-0066, Japan: ${ }^{c}$ Laboratory of \\ Clinical Pharmacokinetics, Graduate School of Pharmaceutical Sciences, Takasaki University of Health and Welfare; \\ 60 Nakaorui-machi, Takasaki, Gunma 370-0033, Japan: and ${ }^{d}$ Laboratory of Drug Delivery System, Faculty of \\ Pharmaceutical Sciences, Setsunan University; 45-1 Nagaotoge-cho, Hirakata, Osaka 573-0101, Japan. \\ Received August 30, 2020; accepted October 27, 2020
}

Our previous report indicated that Snail-induced epithelial-mesenchymal transition (EMT) enhanced P-glycoprotein (P-gp) function and drug resistance to P-gp substrate anticancer drug in a human non-small cell lung cancer (NSCLC) cell line, HCC827. Our objective is to evaluate the changes in the mRNA and protein expression levels and the functions of multidrug resistance-associated protein (MRP) 2, MRP5 and breast cancer resistance protein (BCRP). Snail-expressing HCC827 cells showed increased mRNA levels of Snail and a mesenchymal marker vimentin, and decreased mRNA levels of an epithelial marker E-cadherin after transduction, indicating that Snail had induced EMT consistent with our previous reports. The mRNA level of MRP2 was significantly decreased, while that of MRP5 remained unchanged, in Snail-expressing cells. The expression levels of MRP2 and MRP5 proteins in whole-cell homogenate were unchanged in Snailexpressing cells, but MRP5 protein showed significantly increased membrane localization. Snail-transduction increased the efflux transport of 5-(and-6)-carboxy-2',7'-dichlorofluorescein (CDCF), a substrate of MRP2, 3 and 5. This increase was blocked by MK571, which inhibits MRP1, 2, and 5. Toxicity of cisplatin, a substrate of MRP2 and 5, was significantly decreased in Snail-expressing cells. BCRP mRNA and protein levels were both decreased in Snail-expressing cells, which showed an increase in the intracellular accumulation of 7-ethyl-10-hydroxycamptothecin (SN-38), a BCRP substrate, resulting in reduced viability. These results suggested that MRP5 function appears to be increased via an increase in membrane localization, whereas the BCRP function is decreased via a decrease in the expression level in HCC827 cells with Snail-induced EMT.

Key words Snail; non-small cell lung cancer cell; epithelial-to-mesenchymal transition; multidrug resistance-associated protein (MRP); breast cancer resistance protein (BCRP); membrane localization

\section{INTRODUCTION}

Despite advances in cancer chemotherapy, the prognosis for non-small cell lung cancer (NSCLC) remains poor, ${ }^{1,2}$ in part owing to the acquisition of drug resistance, e.g., due to increased expression and/or function of efflux transporters such as P-glycoprotein (P-gp), leading to increased drug efflux from tumor cells. ${ }^{3,4)}$ Another important issue is the frequent development of metastasis, which is promoted by epithelial-tomesenchymal transition (EMT), i.e., conversion of epithelial cancer cells into mesenchymal ones with enhanced migratory and invasive properties. ${ }^{5)}$ EMT is characterized by a decrease in E-cadherin (E-Cad), an epithelial marker, and an increase in vimentin (VIM), a mesenchymal marker. ${ }^{6,7)}$ The Snail family of zinc finger-type transcription factors, which is composed of three genes, SNAI 1 (Snail), SNAI 2 (Slug) and SNAI 3 (Smuc), promotes EMT by binding to the E-box in the E-Cad promoter. ${ }^{8}$ Snail in particular strongly suppresses the transcription of E-cad, and promotes EMT.9)

P-gp, an ATP-binding cassette transporter, is highly expressed in malignant cancers and excretes various anticancer drugs from the intracellular to the extracellular space, resulting in increased drug resistance. ${ }^{10,11)}$ We previously showed that when EMT is induced by Snail expression in NSCLC, the function of P-gp is enhanced without any increase of its mRNA level. ${ }^{12,13)}$ Moreover, we have reported that P-gp transport activity does not necessarily depend on the protein expression level in the whole cell, because P-gp function is also regulated by scaffold proteins, such as ezrin, radixin and moesin, which control its membrane localization. ${ }^{14-16)}$ Therefore, the enhancement of P-gp function in EMT might be due not to a change in its protein level, but rather to a change of its localization to the membrane.

Multidrug resistance-associated proteins (MRPs) and breast cancer resistance protein (BCRP) are also efflux transporters belonging to the ATP binding cassette transporter family, alongside P-gp, and changes in their expression are related to the development of drug resistance in many malignant cancers, including NSCLC. ${ }^{17,18}$ However, it remains unclear whether EMT enhances the function of efflux transporters other than P-gp in NSCLC cells. Thus, we hypothesized that the functions of MRPs and BCRP might also be enhanced in NSCLC showing Snail-induced EMT. We particularly focused on MRP2 and MRP5 among the MRP family, since these transporters contribute to drug-resistance to cisplatin. Used as first-line chemotherapy for NSCLC worldwide, cisplatin is well known to be a substrate of MRP2, and MRP5 is also associated with resistance to this drug. ${ }^{19,20)}$ On the other hand, 
irinotecan is also widely used to treat NSCLC, and its active metabolite SN-38 is excreted by BCRP. Therefore, we evaluated the changes in the mRNA and protein expression levels of MRP2, MRP5 and BCRP, as well as the changes in the functions of these transporters, associated with Snail-induced EMT in a human NSCLC cell line, HCC827, and investigated their relationship to drug resistance.

\section{MATERIALS AND METHODS}

Chemicals 7-Ethyl-10-hydroxycamptothecin (SN-38) was purchased from Sigma-Aldrich (St. Louis, MO, U.S.A.), and 5-(and-6)-carboxy-2',7'-dichlorofluorescein diacetate (mixed isomer) (CDCFDA) and 5-(and-6)-carboxy-2',7'dichlorofluorescein (CDCF) were purchased from PromoKine (Heidelberg, Germany). All other reagents were commercial products of reagent grade.

Cell Culture and Transduction of Snail Gene HCC 827 cells were purchased from American Type Culture Collection. The basal medium of HCC827 cells was obtained by adding fetal bovine serum (FBS), penicillin and streptomycin to Dulbecco's modified Eagle's medium (D-MEM). Cells were cultured in basal medium at $37^{\circ} \mathrm{C}$ in a humidified atmosphere of $5 \% \mathrm{CO}_{2}$ in air. Human adenovirus serotype 5 vectors (Ad) containing or not containing Snail gene were gifts from Dr. Kajita, ${ }^{21)}$ and were purified as previously described. ${ }^{13)}$ HCC 827 cells were seeded at a density of $5.0 \times 10^{4}$ cells on 24 -well cell culture plates. One day after seeding, cells were transduced with $1.0 \times 10^{9}$ virus particles (VPs)/well.

Measurement of mRNA Expression Level by RTqPCR Total RNA was extracted using TRIzol ${ }^{\mathrm{TM}}$ Reagent at $2 \mathrm{~d}$ after transduction for MRPs and at $5 \mathrm{~d}$ for BCRP. The RNA amount of each sample was measured using NANO DROP LIGHT (Thermo, Waltham, MA, U.S.A.). Complementary DNA was synthesized from $1 \mu \mathrm{g}$ RNA using ReverTra Ace ${ }^{\circledR}$ (Toyobo, Osaka, Japan) and a $\mathrm{T} 100^{\mathrm{TM}}$ Thermal Cycler (Bio-Rad, Hercules, CA, U.S.A.). Real-time PCR was conducted using Power $\mathrm{SYBR}^{\mathrm{TM}}$ Green PCR Master Mix (Applied Biosystems, Carlsbad, CA, U.S.A.) with an Mx3000P qPCR system (Agilent Technologies, Santa Clara, CA, U.S.A.). The target mRNA levels were normalized to the mRNA levels of glyceraldehyde-3-phosphate dehydrogenase (GAPDH) as an internal standard, and the relative expression amount was evaluated by the $\Delta \Delta \mathrm{Ct}$ method. Primers for E-Cad, VIM, Snail, P-gp and GAPDH were as follows: E-cad, F: 5'-CAGCAC GTA CAC AGCCCT AA-3', R: 5'-ACC TGA GGC TTT GGA TTCCT-3', VIM, F: 5'-CGGGAGAAA TTGCAGGAGGA-3'， R: 5'-AAGGTC AAG ACG TGC CAG AG-3', Snail, F: 5'-GAA AGGCCT TCA ACT GCAAA-3', R: 5'-TGA CAT CTG AGT GGG TCT GG-3', BCRP, F: 5'-ACT GGC TTA GAC TCA AGC ACA-3'， R: 5'-ATA GGC CTC ACA GTG ATA ACC A-3', MRP2， F: 5'-ATT GCT TCC ATT GGGCTC CA-3', R: 5'-GGC TGGCCA CAAAAG ACT TG-3', MRP5, F: 5'-GGG AAT GCT TTG TGC AGCG-3'， R: 5'-CACATC AGA ATT CCT GCGCC-3'， GAPDH， F: 5'-TGC ACC ACC AAC TGC TTA GC-3', R: 5'-GGC ATG GAC TGT GGT CAT GAG-3'.

Collection of Whole Cell Homogenate and Isolation of Plasma Membrane Protein The plasma membrane proteins were extracted using a Minute Plasma Membrane Protein Isolation Kit (Invent Biotechnologies, Eden Prairie, MN, U.S.A.) according to the manufacturer's protocol. Briefly, cells trans- fected with Ad Mock or Snail were homogenized in buffer A for 1 min using an ultrasonic disruptor (TOMY SEIKO, Tokyo, Japan) and transferred to a filter cartridge on ice. All subsequent procedures were conducted at $4{ }^{\circ} \mathrm{C}$. After centrifugation at $16000 \times \boldsymbol{g}$ for $30 \mathrm{~s}$, the supernatant was transferred to a new tube and then further centrifuged at $16000 \times \boldsymbol{g}$ for $10 \mathrm{~min}$. The pellet was collected as a total membrane fraction, resuspended in buffer B, and centrifuged at $7800 \times \boldsymbol{g}$ for $5 \mathrm{~min}$. The supernatant was then centrifuged again at $16000 \times \boldsymbol{g}$ for $30 \mathrm{~min}$, and the pellet was collected as plasma membrane (PM) protein fraction for Western blot analysis.

Western Blot Analysis The protein concentrations of samples were determined using a DC protein assay kit with bovine serum albumin as the standard. Homogenate and cell membrane fractions (35 $\mu \mathrm{g}$ protein/lane) were loaded onto an e-PAGEL HR 5-20\% (ATTO Corporation, Tokyo, Japan), electrophoresed for $80 \mathrm{~min}$, and transferred onto a polyvinylidene fluoride (PVDF) membrane (Millipore, Bedford, MA, U.S.A.). The membrane was blocked with $5 \%$ skim milk in tris-buffered saline solution containing Tween 20 (TBS-T) at $4{ }^{\circ} \mathrm{C}$ overnight, washed three times with TBS-T, and incubated for $1 \mathrm{~h}$ at ambient temperature with a primary antibody, antiMRP2 or MRP5 antibody, anti-BCRP antibody, anti-GAPDH antibody. Following three washes with TBS-T, the membrane was incubated with a secondary antibody conjugated with horseradish peroxidase for $1 \mathrm{~h}$, and again washed three times with TBS-T. Target protein amounts were analyzed using the ECL $^{\mathrm{TM}}$ Prime Western blotting Detection Reagent (GE Healthcare, Buckinghamshire, U.K.) and LAS 3000 Luminescent Image Analyzer (Fuji Photo Film, Tokyo, Japan). The optical density value was determined using equal-sized pixels for relative quantification. Each target density value was normalized to actin expression levels in homogenate and plasma membrane fractions.

Uptake Studies We chose SN-38, which is an active metabolite of irinotecan and a BCRP substrate, ${ }^{22-24)}$ and CDCF, which is a common substrate of MRP2, 3 and $5,{ }^{25-27)}$ to evaluate the transport activities of BCRP and MRPs. Uptake activities were measured using cells at 2 and $5 \mathrm{~d}$ after transduction, at $37^{\circ} \mathrm{C}$. Wells were washed twice with Hank's balanced salt solution containing 4-(2-hydroxyethyl)-1-piperazine-ethanesulfonic acid (HBSS-HEPES) ( $\mathrm{pH} \mathrm{7.4)}$ at $37^{\circ} \mathrm{C}$. To evaluate BCRP function or MRPs function, $2 \mu \mathrm{M}$ SN-38 or $5 \mu \mathrm{M}$ CDCFDA, which is a cell-permeable compound that is hydrolyzed by intracellular esterase to fluorescent CDCF, was added, respectively, with or without $10 \mu \mathrm{M}$ MK571 as a MRP1, 2 and 5 inhibitor. $^{28)}$ One hour after addition of SN-38 in HBSS-HEPES or CDCFDA in Opti-MEM solution, the culture plate was washed three times with cold PBS to stop the reaction. The measurement conditions for SN-38 and CDCF are described under "Quantitation of intracellular concentrations of SN-38 and CDCF."

Efflux Assay of CDCF Efflux assay was performed at $2 \mathrm{~d}$ after transduction. Wells were washed twice with cold PBS on ice. Cells were incubated in $5 \mu \mathrm{M}$ CDCFDA/Opti-MEM solution with or without $10 \mu \mathrm{M}$ MK 571, diluted with Opti-MEM, and kept on ice. After $30 \mathrm{~min}$ incubation on ice, the cells were washed twice with cold PBS and warmed for $2 \mathrm{~min}$ at $37^{\circ} \mathrm{C}$, then Opti-MEM containing or not containing $10 \mu \mathrm{M}$ MK 571 was added. The cells were washed three times with cold PBS to stop the reaction. Initial uptake was determined at $30 \mathrm{~min}$ 
after the CDCFDA incubation on ice. The measurement conditions for CDCF are described under "Quantitation of intracellular concentrations of SN-38 and CDCF."

Quantitation of Intracellular Concentrations of $\mathrm{SN}-38$ and CDCF Cells were lysed with $0.02 \%$ sodium dodecyl sulfate (SDS) solution to evaluate SN-38 intracellular accumulation, and the supernatant was purified on 96-well filter plates. Each purified sample was measured by HPLC. The HPLC system consisted of a constant-flow pump (LC-10AT; Shimadzu, Kyoto, Japan), a fluorescence detector (RF-10AXL; Shimadzu) set at an excitation wavelength of $380 \mathrm{~nm}$ and emission wavelength of $556 \mathrm{~nm}$, an automatic sample injector (SIL-10A; Shimadzu) and an integrator (Chromatopac CR7A plus; Shimadzu). A Mightysil RP-18 GP Aqua (5 $\mu \mathrm{m}$, Kanto Kagaku, Tokyo, Japan) column was used at $30^{\circ} \mathrm{C}$. The mobile phase consisted of $20 \mathrm{mM}$ phosphate buffer ( $\mathrm{pH} 2.0$ )/acetonitrile $(65 / 35)$, and the flow rate was $1.0 \mathrm{~mL} / \mathrm{min}$. On the other hand, cells were lysed with $0.1 \mathrm{~mol} / \mathrm{L} \mathrm{NaOH}$ for the evaluation of CDCF intracellular accumulation. The lysate sample was examined with a WALLAC Multilabel/Luminescence Counter (PerkinElmer, Inc., Waltham, MA, U.S.A.), with excitation and emission wavelengths of $485 \mathrm{~nm}$ and $538 \mathrm{~nm}$, respectively. In addition, cells lysed with $\mathrm{NaOH}$ were used for the measurement of protein concentration according to the Lowry method. Changes in the intracellular accumulation of drugs were determined by the cell-to-medium ratio ( $\mathrm{C} / \mathrm{M}$ ratio).

$\mathrm{C} / \mathrm{M}$ ratio of $\mathrm{SN}-38$ and $\mathrm{CDCF}$ was calculated as:

$$
\begin{aligned}
& \mathrm{C} / \mathrm{M} \text { ratio }(\mu \mathrm{L} / \mathrm{mg} \text { protein }) \\
& =\frac{\text { Concentration of test drug in the cell lysate }(\mu \mathrm{M})}{\text { Extracellular concentration }(10 \mu \mathrm{M})} \\
& \quad \times \text { Protein concentration }(\mathrm{mg} / \mu \mathrm{L})
\end{aligned}
$$

The excretion rate of CDCF was calculated as:

$$
\begin{aligned}
& X_{0}=\frac{\text { Initial uptake of CDCF }(\mu \mathrm{M})}{\text { Protein concentration }(\mathrm{g} / \mathrm{L})} \\
& X_{1}=\frac{\text { CDCF concentration after incubation at } 37^{\circ} \mathrm{C}(\mu \mathrm{M})}{\text { Protein concentration }(\mathrm{g} / \mathrm{L})}
\end{aligned}
$$

Efflux rate $(\mathrm{nmol} / \mathrm{min} / \mathrm{g}$ protein $)=\frac{\left(X_{0}-X_{1}\right)}{\text { Incubation at } 37^{\circ} \mathrm{C}(\min )}$

Cell Viability Assay HCC827 cells were seeded at $1 \times 10^{4}$ cells/well on a 96-well culture plate and transduced the following day. After $2 \mathrm{~d}$, cisplatin was added to each well for $3 \mathrm{~d}$. In a separate experiment, $5 \mathrm{~d}$ after transduction, $\mathrm{SN}-38$ was added to each well for $2 \mathrm{~d}$. To assess the cytotoxicity of cisplatin or SN-38, alamarBlue ${ }^{\circledR}$ reagent (AbD Serotec, Dusseldorf, Germany) was added, and the absorbance was measured at $535 \mathrm{~nm}$ and the reference wavelength was set at $650 \mathrm{~nm}$. The viability was calculated from these values in accordance with the manufacturer's instructions.

Statistical Analysis All experimental data are shown as mean \pm coefficient of variation $(\mathrm{CV})$ in mRNA levels and mean \pm standard error (S.E.) in other data. Student's $t$-test was used for comparison between two groups, and Holm's test was used for more than two groups.

\section{RESULTS}

Effect of Snail on the Expression of EMT Markers, and MRP2 and MRP5 In Snail-expressing HCC827 cells, the mRNA expression level of E-Cad was significantly decreased, whereas that of VIM was significantly increased compared with Mock cells (Fig. 1A). In addition, the MRP2 mRNA expression level in Snail-expressing cells was significantly lower

(A) Snail and EMT markers mRNA (Day 2)

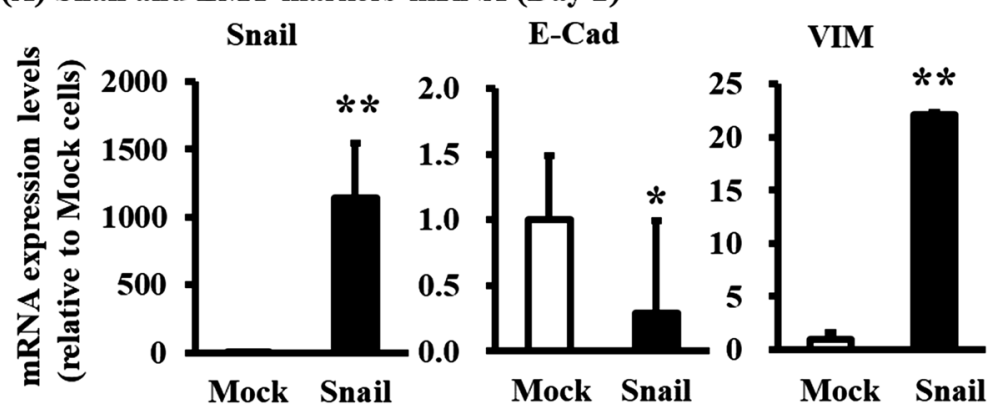

(B) MRP2 and MRP5 mRNA (Day 2)

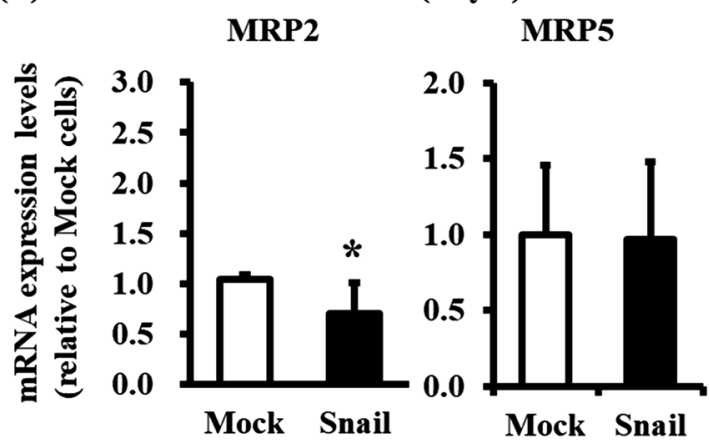

Fig. 1. mRNA Expression of Snail, EMT Markers, MRP2 and MRP5 at $2 \mathrm{~d}$ after Transduction

Open and closed bars show Mock and Snail-expressing cells, respectively. mRNA expression levels of Snail, the EMT markers E-cad and VIM, MRP2 and MRP5 were normalized to GAPDH. Results are shown as the mean \pm CV $(n=6-8) .{ }^{*} p<0.05,{ }^{* *} p<0.01$. 

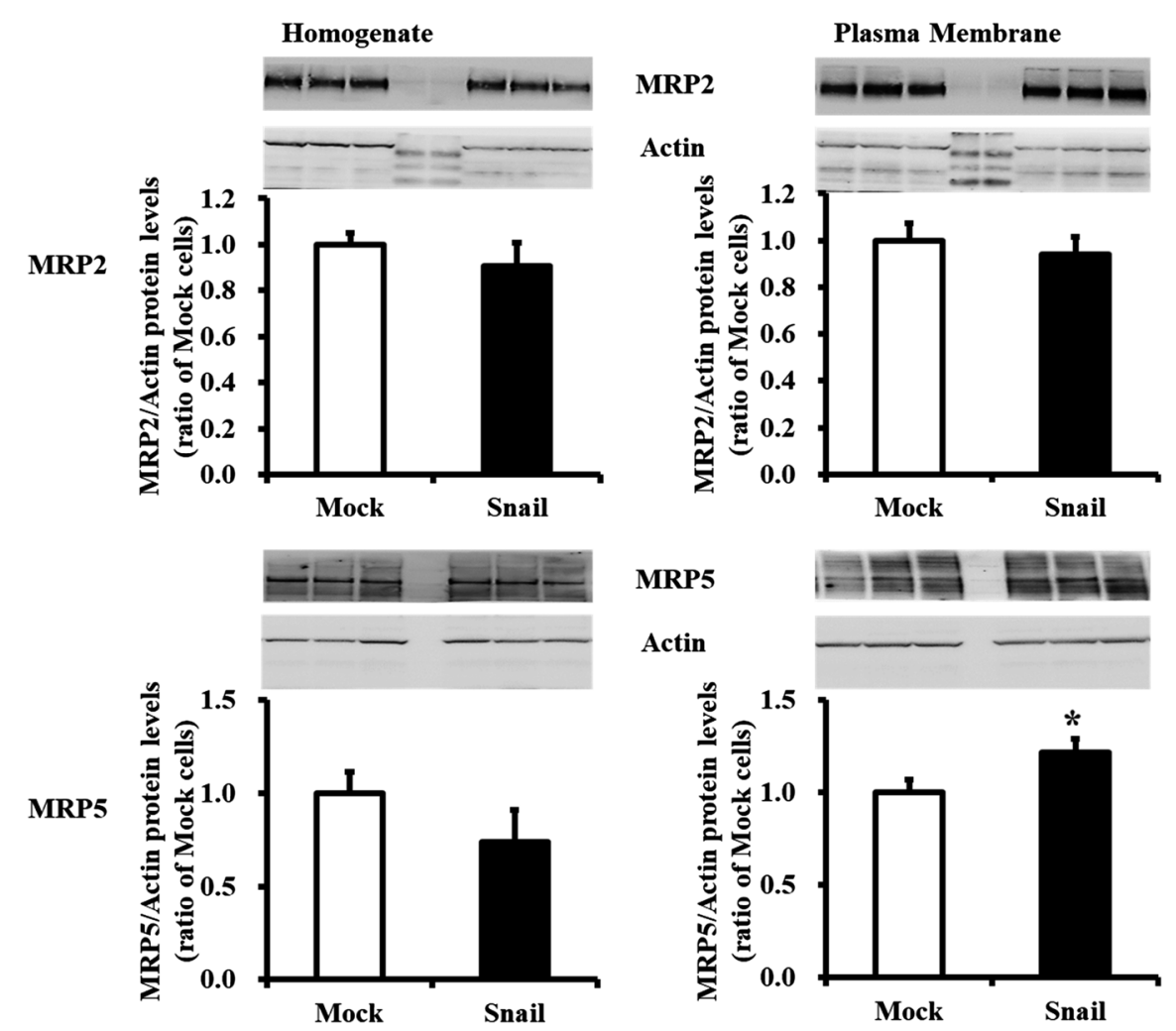

Fig. 2. Protein Expression Levels of MRP2 and 5 in Whole-Cell Homogenate and Plasma Membrane Fraction at 2 d after Transduction

Open and closed bars show Mock and Snail-expressing cells, respectively. Amounts of MRP2 and MRP5 in the homogenate and in the plasma membrane fraction were normalized to actin in each fraction. Samples from Mock- and Snail-transduced cells were loaded in triplicate lanes. Molecular marker was loaded in two lanes between Mock and Snail for MRP2 and in one lane between Mock and Snail for MRP5. Results are given as the mean \pm S.E. $(n=4)$. ${ }^{*} p<0.05$.

than that in Mock cells, while MRP5 mRNA was not significantly changed (Fig. 1B).

Changes in Expression of MRP2 and MRP5 Proteins Induced by Snail The expression levels of MRP2 protein (normalized by actin expression) in the homogenate and the plasma membrane were not changed in Snail-expressing cells, compared with Mock cells. MRP5 protein level in the plasma membrane fraction of Snail-expressing cells was significantly higher than that in Mock cells, though it was unchanged in the whole-cell homogenate (Fig. 2).

Functional Changes of MRP2 and MRP5 in SnailExpressing Cells When Snail-expressing cells were exposed to CDCFDA, a precursor of $\mathrm{CDCF}$, the $\mathrm{C} / \mathrm{M}$ ratio of $\mathrm{CDCF}$, a substrate of MRP2, 3 and $5,{ }^{25-27)}$ was significantly decreased compared to that in Mock cells, and the efflux rate was significantly increased. Treatment with MK571 in Snail-expressing cells, an inhibitor of MRPs (MRP1, 2, 5) ${ }^{28)}$ significantly increased the $\mathrm{C} / \mathrm{M}$ ratio of $\mathrm{CDCF}$ in Snail-expressing cells, and correspondingly reduced the efflux rate of CDCF compared with Snail-expressing cells not treated with the inhibitor (Fig. 3).

Effect of Snail Transduction on Susceptibility to Cisplatin Cisplatin treatment significantly decreased the viability of both Mock and Snail-expressing cells. However, in the presence of $20 \mu \mathrm{M}$ cisplatin, the viability of Snail-expressing cells was significantly higher than that of Mock cells (Fig. 4).

Effect of Snail on the Expression of EMT Markers and BCRP E-Cad mRNA was significantly decreased and VIM mRNA was significantly increased at $5 \mathrm{~d}$ after transduction of
Snail. The BCRP mRNA expression level in Snail-expressing cells was significantly lower than that in Mock cells (Fig. 5A). Moreover, BCRP protein levels in the homogenate and in the plasma membrane were both significantly decreased by Snail overexpression (Fig. 5B).

Effect of Snail Transduction on BCRP Function and Susceptibility of Cells to SN-38 When cells were exposed to $\mathrm{SN}-38, \mathrm{C} / \mathrm{M}$ ratio of $\mathrm{SN}-38$ was significantly increased in Snail-expressing cells compared with Mock cells (Fig. 6A). Correspondingly, the viability of Snail-expressing cells was significantly lower than that of Mock cells (Fig. 6B).

\section{DISCUSSION}

In this work, we first confirmed that Snail-expressing HCC827 cells showed increased mRNA levels of Snail and a mesenchymal marker VIM, and decreased mRNA levels of an epithelial marker E-Cad at both 2 and $5 \mathrm{~d}$ after transduction (Figs. 1, 5), indicating that Snail had induced EMT consistent with our previous reports. ${ }^{12,13)}$ Although the number of culture days was different between MRP and BCRP, an appropriate time point at which each transporter function could be evaluated was used. Here, we found that the mRNA level of MRP2 was significantly decreased, while that of MRP5 remained unchanged, in Snail-expressing cells compared to vector-transduced (Mock) cells (Fig. 1). The expression level of neither protein in the whole-cell homogenate was changed in Snail-expressing cells, but the membrane localization of MRP5, though not MRP2, was significantly increased 

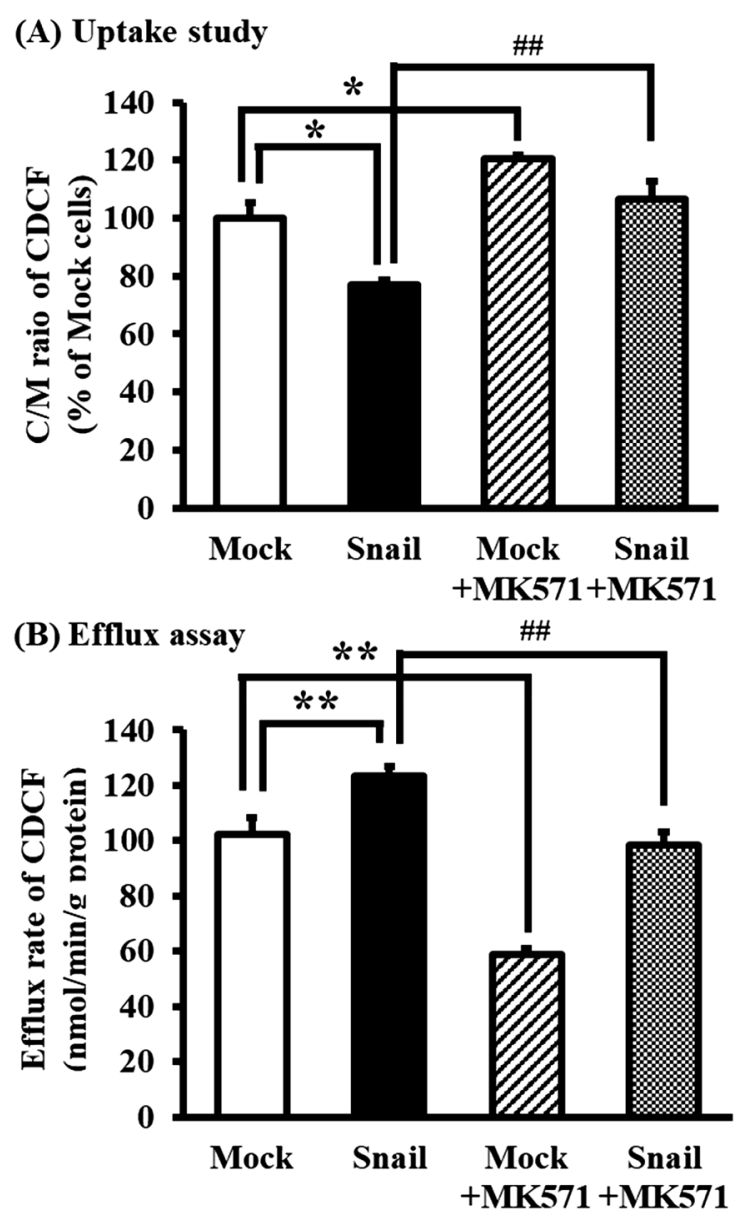

Fig. 3. Changes of MRP2 and MRP5 Transport Functions at $2 \mathrm{~d}$ after Transduction

Uptake and efflux of the MRPs substrate CDCF were evaluated at $2 \mathrm{~d}$ after transduction. Open and closed bars show Mock and Snail-expressing cells, respectively. Uptake study and efflux assay were conducted using $5 \mu \mathrm{M}$ CDCFDA at $37^{\circ} \mathrm{C}$. Cells were preincubated with Opti-MEM containing or not containing $10 \mu \mathrm{M}$ MK571 for $30 \mathrm{~min}$. (A) In the uptake study, the $\mathrm{C} / \mathrm{M}$ ratio of $\mathrm{CDCF}$ was determined. Results are shown as the mean \pm S.E. $(n=3) * p<0.05$ compared with Mock cells. $\# p<0.01$ compared with Snail cells. (B) In the efflux assay, cells were treated with CDCFDA for $30 \mathrm{~min}$ on ice, then incubated with Opti-MEM containing or not containing $10 \mu \mathrm{M} \mathrm{MK571} \mathrm{for} 2 \mathrm{~min}$ at $37^{\circ} \mathrm{C}$. Results are shown as the mean $\pm \mathrm{S}$.E. $(n=6) . * p<0.05, * * p<0.01$ compared with Mock cells. ${ }^{\#} p<0.01$ compared with Snail cells.

in Snail-expressing cells (Fig. 2). We have also shown that Western blot quantification is consistent with qualitative evaluation using confocal microscopy. ${ }^{29,30)}$ These results suggested that the transfer of MRP5 to the plasma membrane, where it excretes a substrate, was increased. In addition, our plasma membrane fraction was shown to be well purified, since CD26, a cell membrane marker protein, ${ }^{31)}$ was mainly expressed in the plasma membrane fraction (Supplementary Fig. 3). Moreover, actin was detected in the plasma membrane fraction, consistent with our previous studies. ${ }^{16,32)}$

Snail significantly reduced the $\mathrm{C} / \mathrm{M}$ ratio and increased the efflux rate of CDCF, which is a substrate of MRPs (MRP 2, $3,5)^{25-27)}$ (Fig. 3). CDCF transport increased by about $20 \%$ with the transduction of Snail. This increase was canceled by MK571, an inhibitor of MRP1, 2, and $5,{ }^{28)}$ leading to values similar to those of untreated Mock. Moreover, there is considerable evidence that MRP2 and MRP5 are both involved in MK571-inhibitable CDCF excretion. ${ }^{28}$ Therefore, our results indicate that the function(s) of MRP2 and/or MRP5 might

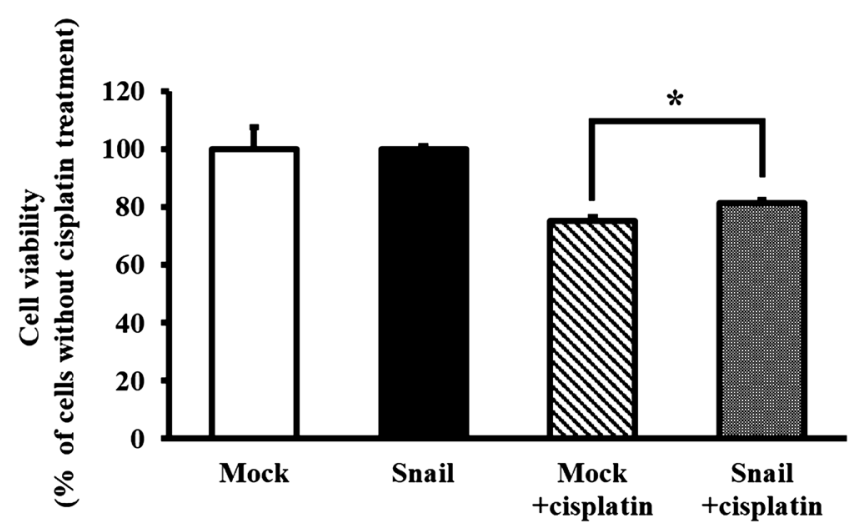

Fig. 4. Change of Cisplatin Resistance at $2 \mathrm{~d}$ after Transduction

Cells were treated with $20 \mu \mathrm{M}$ cisplatin in Opti-MEM for $72 \mathrm{~h}$. Open and closed bars show Mock and Snail-expressing cells, respectively. Hatched and dotted bars show Mock and Snail-expressing cells with cisplatin treatment, respectively. Mock and Snail groups were normalized to each cell without cisplatin treatment. Results are shown as the mean \pm S.E. $(n=4-6) . * p<0.05$ compared with Mock + cisplatin cells.

be enhanced in Snail-transfected cells. On the other hand, factors other than MRP may be involved in the increase of CDCF excretion by Snail. However, it has been reported that P-gp was not involved in CDCF excretion ${ }^{33)}$ and BCRP function was not enhanced by Snail (Fig. 6), suggesting that these transporters would not have a significant effect on this study. In addition, we found that resistance to cisplatin toxicity was slightly but significantly greater in Snail-expressing cells than Mock cells (Fig. 4), although further clinical study is needed to determine whether this change affects clinical situations. Cisplatin is well known to be a substrate of MRP2, ${ }^{19)}$ and in addition, the cisplatin resistance of MRP5-transfected cells is significantly higher than that of vector-transfected cells. ${ }^{20)}$ Moreover, MRP5 gene expression in autopsy samples of lung cancer from patients exposed to platinum drugs was higher than that in samples from non-exposed patients. ${ }^{34)}$ Although MRP2 expression levels in NSCLC cell lines and NSCLC clinical samples are very low, MRP5 has been reported to be well expressed in all samples. ${ }^{35)}$ On the other hand, in the transport of CDCF, the transport activities of these two transporters have been shown to be not significantly different. ${ }^{25)}$ Therefore, in this study, it is considered that MRP5 contributes more to the transport of CDCF and cisplatin than MRP2. In other words, Snail may induce cisplatin resistance via functional enhancement of MRP5. Overall, the present results and previous findings suggest that Snail-induced enhancement of MRP5 function via increased membrane localization of this transporter might be a major factor in the increased drug resistance, although it cannot be ruled out that the MRP2 was activated by a mechanism other than the increase in the expression level on the membrane. It should be noted that the mRNA and protein levels of other MRPs (MRP1, 3, 4) were differentially altered by Snail transduction (Supplementary Figs. 1, 2), but it seems likely that only MRP4 among them was functionally enhanced, since only MRP4 showed significantly increased membrane localization (Supplementary Fig. 2). It was reported that MRP4 cannot transport $\mathrm{CDCF}^{25)}$ and there is little evidence that it can transport cisplatin or contribute to cisplatin resistance. Therefore, it seems unlikely that MRP1, 3, and 4 contribute to either the transport of CDCF or 
(A) Snail, E-Cad, VIM and BCRP mRNA (Day 5)

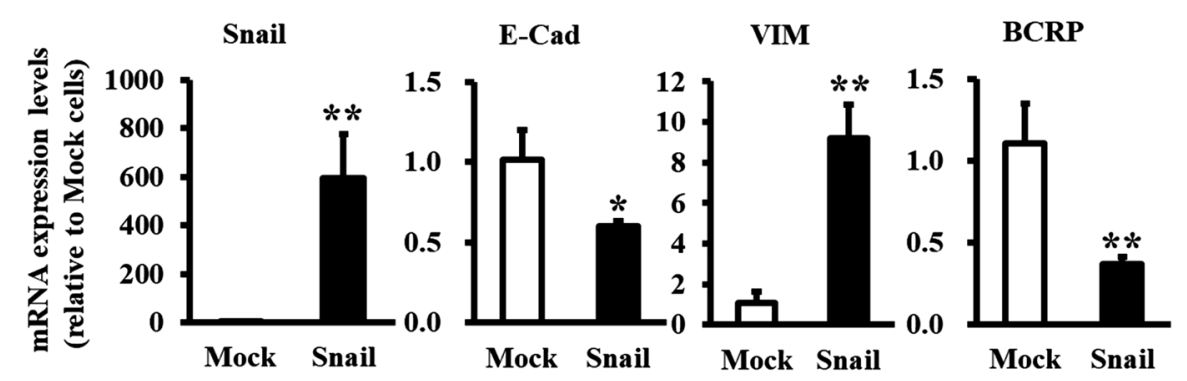

(B) BCRP protein expression (Day 5)
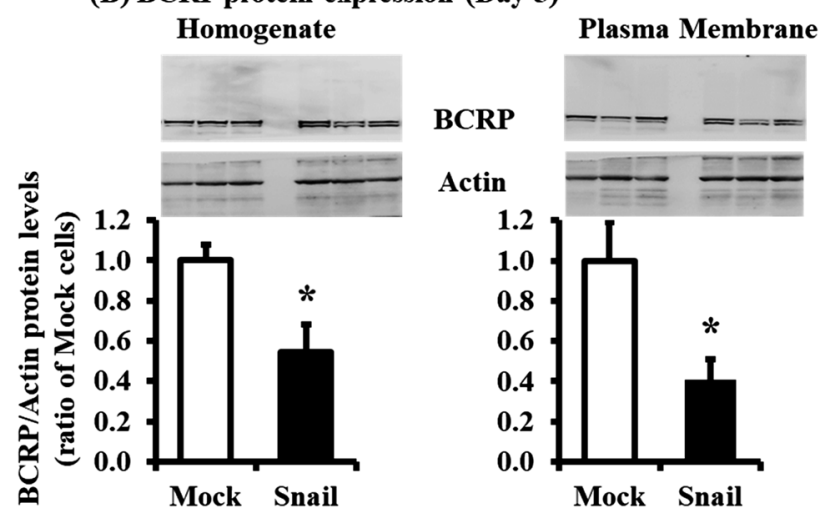

Fig. 5. Expression of Snail, EMT Markers and BCRP at $5 \mathrm{~d}$ after Transduction

Open and closed bars show Mock and Snail-expressing cells, respectively. (A) mRNA expression levels of Snail, the EMT markers E-Cad and VIM, and BCRP were normalized to GAPDH. Results are given as the mean $\pm \mathrm{CV}(n=3-4)$. (B) Amounts of BCRP in the homogenate and the plasma membrane fraction were normalized to actin in each fraction. Results are given as the mean \pm S.E. $(n=3-4) . * p<0.05, * * p<0.01$.

the resistance to cisplatin.

We found that protein expression levels of BCRP in both the homogenate and the plasma membrane fraction were significantly reduced, in accordance with the change in BCRP mRNA expression (Fig. 5). Moreover, the C/M ratio of SN-38, which is a BCRP substrate and an anticancer drug, in Snailexpressing cells was significantly increased compared to that in Mock cells (Fig. 6). The cytotoxicity of SN-38 was strongly enhanced in Snail-expressing cells; i.e., the viability of Snailexpressing cells was significantly lower than that of Mock cells in the presence of SN-38 (Fig. 6). These results indicate that Snail decreases BCRP function, thereby increasing the intracellular accumulation of and susceptibility to substrate anticancer drugs.

Our findings suggest that Snail-induced EMT reduces the sensitivity of HCC 827 cells to the MRP substrate drug, cisplatin, by increasing the level of MRP5 expression. In contrast, the sensitivity to the BCRP substrate drug SN-38 is enhanced due to decreased expression and function of BCRP. One of the mechanisms that causes the difference in the function of these transporters might be the regulation of gene expression of MRPs and BCRP by Snail. Pregnane X receptor (PXR) and constitutive androstane receptor (CAR) induce MRP2-4 gene expression, and peroxisome proliferator-activated receptor gamma (PPAR $\gamma)$ induces BCRP gene expression. ${ }^{36)}$ Moreover, nuclear factor E2-related factor 2 (Nrf2) has been shown to induce MRPs and BCRPs. ${ }^{37,38)}$ Furthermore, Snail suppresses PPAR $\gamma$ expression. ${ }^{39)}$ This report is consistent with our results of reduced BCRP expression in Snail expressing cells. However, Snail does not increase some transcription factors such as PXR and $\mathrm{CAR},{ }^{40)}$ and there are few reports on whether Snail affects Nrf2. If Snail inhibits Nrf2 expression or activity, expression of the MRP1-5 family should be reduced, but our results do not show this. Furthermore, little is known about the factors involved in the gene expression mechanism of MRP5. ${ }^{41)}$ Therefore, it is considered that Snail separately regulates the gene expression of MRPs and BCRP. Alternatively, the difference in time post-Snail transduction may have produced a difference in the expression of MRP and BCRP. On the other hand, it has been reported that Snail enhances the expression of BCRP in MCF-7. ${ }^{42)}$ This is inconsistent with the results of this study. However, the other report indicated that transforming growth factor (TGF)- $\beta$ induces EMT via the stimulation of Snail in MCF-7, and at this time, the expression of BCRP is reduced. ${ }^{43)}$ In the same report, it is also shown that BCRP expression reappears when EMT like cells are undergo mesenchymal-epithelial transition (MET). These reports suggest that BCRP expression changes depending on the timing of EMT. Therefore, it is considered that our results reflect BCRP expression during EMT formation, although the detailed mechanism remains unclear. Next, focusing on posttranslational modification, our previous studies showed that P-gp function in several cell lines is regulated not simply by the mRNA expression level, but also by membrane localization, ${ }^{14-16,32)}$ which in turn is controlled via ezrin, radixin and moesin (ERM) proteins. In particular, we recently reported that BCRP and P-gp transport functions in $\mathrm{HCC} 827$ cells are regulated by ezrin and moesin. ${ }^{44,45}$ Moreover, we showed that the function of P-gp is enhanced without any increase in its mRNA level in HCC827 cells with Snail-induced EMT. ${ }^{12,13)}$ 
(A) BCRP transport function

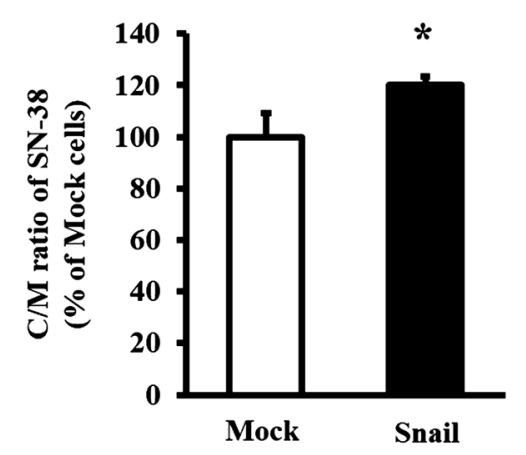

(B) Cell viability

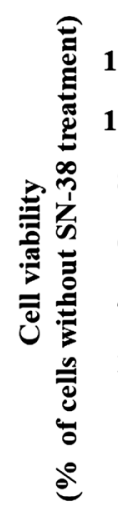

Fig. 6. Functional Change of BCRP at $5 \mathrm{~d}$ after Transduction

Uptake and cell viability were evaluated at $5 \mathrm{~d}$ after transduction. Open and closed bars show Mock and Snail-expressing cells, respectively. (A) Uptake study was conducted to evaluate BCRP transport function using $2 \mu \mathrm{M} \mathrm{SN}-38$ at $37^{\circ} \mathrm{C}$. After $1 \mathrm{~h}, \mathrm{C} / \mathrm{M}$ ratio of SN-38 was determined. (B) Cells were treated with $1 \mu \mathrm{M}$ SN-38 for $48 \mathrm{~h}$. The cytotoxicity of SN-38 was determined. Hatched and dotted bars show Mock and Snail-expressing cells with SN-38 treatment, respectively. Mock and Snail groups were normalized to each cell without SN-38 treatment. Results are given as the mean \pm S.E. $(n=3-4)$. ${ }^{* *} p<0.01$ compared with Mock $+\mathrm{SN}-38$ cells.

Furthermore, Snail-induced increase in moesin expression was involved in the mechanism of P-gp hyperactivity. ${ }^{46)}$ However, Snail-induced decline in BCRP function was inconsistent with increased expression of Msn. It is considered that this is because the BCRP expression levels on the membrane were reduced due to the significant decrease in the BCRP in whole cells even when Msn was significantly increased. Other researchers have indicated that Snail regulates the expression of ERM proteins. ${ }^{47-49)}$ These findings are all consistent with the idea that the efflux transport function of MRP5 might depend on Snail-mediated changes in membrane localization, but not transcriptional regulation. In addition, previous reports indicated that radixin functions as a scaffold for MRP in the liver, but PDZK1 functions as a scaffold for BCRP in the digestive tract. ${ }^{14,22)}$ Therefore, the factors that act as scaffolds for MRP and BCRP and regulate those transporter functions are different, and it is considered that Snail is responsible for the alteration in the expression of these factors. Further studies will be needed to define the regulatory mechanisms in detail.

\section{CONCLUSION}

The present results indicate that MRPs and BCRP are regulated differently in HCC827 cells with Snail-induced EMT. Specifically, the function of MRP5 appears to be increased via an increase in membrane localization, whereas the function of BCRP is decreased via a decrease in the expression level. Thus, changes in cell exposure to anticancer drugs may occur, depending upon whether the drugs are substrates of MRPs or BCRP. In particular, the cytotoxic effect of BCRP substrates is likely to be enhanced in lung cancer cells after EMT.

Acknowledgments The authors thank Masahiro Kajita for the gift of Ad vectors. This work was supported by JSPS KAKENHI Grant Numbers 18K06793 and 19K16451, and Research Grants from the Takeda Science Foundation.

Conflict of Interest The authors declare no conflict of interest.

Supplementary Materials The online version of this article contains supplementary materials.

\section{REFERENCES}

1) Torre LA, Bray F, Siegel RL, Ferlay J, Lortet-Tieulent J, Jemal A. Global cancer statistics, 2012. CA Cancer J. Clin., 65, 87-108 (2015).

2) Toschi L, Rossi S, Finocchiaro G, Santoro A. Non-small cell lung cancer treatment (r)evolution: ten years of advances and more to come. Ecancermedicalscience, 11, 787 (2017).

3) Triller N, Korosec P, Kern I, Kosnik M, Debeljak A. Multidrug resistance in small cell lung cancer: expression of P-glycoprotein, multidrug resistance protein 1 and lung resistance protein in chemonaive patients and in relapsed disease. Lung Cancer, 54, 235-240 (2006).

4) Yokoyama $H$, Ishida $T$, Sugio $K$, Inoue $T$, Sugimachi $K$. Immunohistochemical evidence that P-glycoprotein in non-small cell lung cancers is associated with shorter survival. Surg. Today, 29, 1141-1147 (1999).

5) Thiery JP. Epithelial-mesenchymal transitions in tumour progression. Nat. Rev. Cancer, 2, 442-454 (2002).

6) Blick T, Widodo E, Hugo H, Waltham M, Lenburg ME, Neve RM, Thompson EW. Epithelial mesenchymal transition traits in human breast cancer cell lines. Clin. Exp. Metastasis, 25, 629-642 (2008).

7) Cowin P, Welch DR. Breast cancer progression: controversies and consensus in the molecular mechanisms of metastasis and EMT. $J$. Mammary Gland Biol. Neoplasia, 12, 99-102 (2007).

8) Chiang C, Ayyanathan K. Characterization of the E-box binding affinity to snag-zinc finger proteins. Mol. Biol. (Mosk), 46, 907-914 (2012).

9) Argast GM, Krueger JS, Thomson S, Sujka-Kwok I, Carey K, Silva S, O'Connor M, Mercado P, Mulford IJ, Young GD, Sennello R, Wild R, Pachter JA, Kan JL, Haley J, Rosenfeld-Franklin M, Epstein DM. Inducible expression of TGFbeta, snail and Zeb1 recapitulates EMT in vitro and in vivo in a NSCLC model. Clin. Exp. Metastasis, 28, 593-614 (2011).

10) Zou F, Seike M, Noro R, Kunugi S, Kubota K, Gemma A. Prognostic significance of ABCB1 in stage I lung adenocarcinoma. Oncol. Lett., 14, 313-321 (2017).

11) Pan JH, Han JX, Wu JM, Huang HN, Yu QZ, Sheng LJ. MDR1 single nucleotide polymorphism G2677T/A and haplotype are correlated with response to docetaxel-cisplatin chemotherapy in patients with non-small-cell lung cancer. Respiration, 78, 49-55 (2009).

12) Tomono $T$, Machida $T$, Kamioka $H$, Shibasaki $Y$, Yano $K$, Ogihara T. Entinostat reverses P-glycoprotein activation in snail-overexpressing adenocarcinoma HCC827 cells. PLOS ONE, 13, e0200015 (2018).

13) Tomono T, Yano K, Ogihara T. Snail-induced epithelial-to-mesen- 
chymal transition enhances P-gp-mediated multidrug resistance in HCC827 cells. J. Pharm. Sci., 106, 2642-2649 (2017).

14) Kano T, Wada S, Morimoto K, Kato Y, Ogihara T. Effect of knockdown of ezrin, radixin, and moesin on P-glycoprotein function in HepG2 cells. J. Pharm. Sci., 100, 5308-5314 (2011).

15) Yano K, Otsuka K, Kato Y, Kawabata H, Ohmori S, Arakawa H, Ogihara T. Different regulation of P-glycoprotein function between Caco-2 and Caki-1 cells by ezrin, radixin and moesin proteins. $J$. Pharm. Pharmacol., 68, 361-367 (2016).

16) Yano K, Tomono T, Sakai R, Kano T, Morimoto K, Kato Y, Ogihara $\mathrm{T}$. Contribution of radixin to P-glycoprotein expression and transport activity in mouse small intestine in vivo. J. Pharm. Sci., 102, 2875-2881 (2013).

17) Nagashima $S$, Soda $H$, Oka M, Kitazaki $T$, Shiozawa $K$, Nakamura Y, Takemura M, Yabuuchi H, Fukuda M, Tsukamoto K, Kohno S. BCRP/ABCG2 levels account for the resistance to topoisomerase I inhibitors and reversal effects by gefitinib in non-small cell lung cancer. Cancer Chemother. Pharmacol., 58, 594-600 (2006).

18) Chuman Y, Sumizawa T, Takebayashi Y, Niwa K, Yamada K, Haraguchi M, Furukawa T, Akiyama S, Aikou T. Expression of the multidrug-resistance-associated protein (MRP) gene in human colorectal, gastric and non-small-cell lung carcinomas. Int. J. Cancer, 66, 274-279 (1996).

19) Materna V, Holm PS, Dietel M, Lage H. Kinetic characterization of ribozymes directed against the cisplatin resistance-associated $\mathrm{ABC}$ transporter cMOAT/MRP2/ABCC2. Cancer Gene Ther., 8, 176-184 (2001).

20) Pratt S, Shepard RL, Kandasamy RA, Johnston PA, Perry W 3rd, Dantzig AH. The multidrug resistance protein 5 (ABCC5) confers resistance to 5-fluorouracil and transports its monophosphorylated metabolites. Mol. Cancer Ther., 4, 855-863 (2005).

21) Kajita M, McClinic KN, Wade PA. Aberrant expression of the transcription factors snail and slug alters the response to genotoxic stress. Mol. Cell. Biol., 24, 7559-7566 (2004).

22) Shimizu T, Sugiura T, Wakayama T, Kijima A, Nakamichi N, Iseki S, Silver DL, Kato Y. PDZK1 regulates breast cancer resistance protein in small intestine. Drug Metab. Dispos., 39, 2148-2154 (2011).

23) Nakatomi K, Yoshikawa M, Oka M, Ikegami Y, Hayasaka S, Sano K, Shiozawa K, Kawabata S, Soda H, Ishikawa T, Tanabe S, Kohno S. Transport of 7-ethyl-10-hydroxycamptothecin (SN-38) by breast cancer resistance protein ABCG2 in human lung cancer cells. Biochem. Biophys. Res. Commun., 288, 827-832 (2001).

24) Kawabata S, Oka M, Shiozawa K, Tsukamoto K, Nakatomi K, Soda H, Fukuda M, Ikegami Y, Sugahara K, Yamada Y, Kamihira S, Doyle LA, Ross DD, Kohno S. Breast cancer resistance protein directly confers SN-38 resistance of lung cancer cells. Biochem. Biophys. Res. Commun., 280, 1216-1223 (2001).

25) Pratt S, Chen V, Perry WI 3rd, Starling JJ, Dantzig AH. Kinetic validation of the use of carboxydichlorofluorescein as a drug surrogate for MRP5-mediated transport. Eur. J. Pharm. Sci., 27, 524-532 (2006).

26) Zamek-Gliszczynski MJ, Xiong H, Patel NJ, Turncliff RZ, Pollack GM, Brouwer KL. Pharmacokinetics of 5(and 6)-carboxy-2, $7^{\prime}-$ dichlorofluorescein and its diacetate promoiety in the liver. J. Pharmacol. Exp. Ther., 304, 801-809 (2003).

27) Mannermaa E, Vellonen KS, Ryhanen T, Kokkonen K, Ranta VP, Kaarniranta K, Urtti A. Efflux protein expression in human retinal pigment epithelium cell lines. Pharm. Res., 26, 1785-1791 (2009).

28) Huynh T, Norris MD, Haber M, Henderson MJ. ABCC4/MRP4: a MYCN-regulated transporter and potential therapeutic target in neuroblastoma. Front. Oncol., 2, 178 (2012).

29) Yano K, Sekine S, Nemoto K, Fuwa T, Horie T. The effect of dimerumic acid on LPS-induced downregulation of Mrp2 in the rat. Biochem. Pharmacol., 80, 533-539 (2010).

30) Sekine S, Yano K, Saeki J, Hashimoto N, Fuwa T, Horie T. Oxida- tive stress is a triggering factor for LPS-induced Mrp2 internalization in the cryopreserved rat and human liver slices. Biochem. Biophys. Res. Commun., 399, 279-285 (2010).

31) Lambeir AM, Durinx C, Scharpe S, De Meester I. Dipeptidyl-peptidase IV from bench to bedside: an update on structural properties, functions, and clinical aspects of the enzyme DPP IV. Crit. Rev. Clin. Lab. Sci., 40, 209-294 (2003).

32) Yano K, Shimizu S, Tomono T, Ogihara T. Gastrointestinal hormone cholecystokinin increases P-glycoprotein membrane localization and transport activity in Caco-2 cells. J. Pharm. Sci., 106, 2650-2656 (2017).

33) Feng SQ, Wang GJ, Zhang JW, Xie Y, Sun RB, Fei F, Huang JQ, Wang Y, Aa JY, Zhou F. Combined treatment with apatinib and docetaxel in A549 xenograft mice and its cellular pharmacokinetic basis. Acta Pharmacol. Sin., 39, 1670-1680 (2018).

34) Oguri T, Isobe T, Suzuki T, Nishio K, Fujiwara $Y$, Katoh O, Yamakido M. Increased expression of the MRP5 gene is associated with exposure to platinum drugs in lung cancer. Int. J. Cancer, $\mathbf{8 6}$, 95-100 (2000).

35) Young LC, Campling BG, Voskoglou-Nomikos T, Cole SPC, Deeley RG, Gerlach JH. Expression of multidrug resistance protein-related genes in lung cancer: correlation with drug response. Clin. Cancer Res., 5, 673-680 (1999).

36) Shugarts S, Benet LZ. The role of transporters in the pharmacokinetics of orally administered drugs. Pharm. Res., 26, 2039-2054 (2009).

37) Maher JM, Cheng X, Slitt AL, Dieter MZ, Klaassen CD. Induction of the multidrug resistance-associated protein family of transporters by chemical activators of receptor-mediated pathways in mouse liver. Drug Metab. Dispos., 33, 956-962 (2005).

38) Jigorel E, Le Vee M, Boursier-Neyret C, Parmentier Y, Fardel O. Differential regulation of sinusoidal and canalicular hepatic drug transporter expression by xenobiotics activating drug-sensing receptors in primary human hepatocytes. Drug Metab. Dispos., 34 1756-1763 (2006)

39) Lee YH, Kim SH, Lee YJ, Kang ES, Lee BW, Cha BS, Kim JW, Song DH, Lee HC. Transcription factor Snail is a novel regulator of adipocyte differentiation via inhibiting the expression of peroxisome proliferator-activated receptor $\gamma$. Cell. Mol. Life Sci., 70, 3959-3971 (2013)

40) Wang H, Li JM, Wei W, Yang R, Chen D, Ma XD, Jiang GM, Wang BL. Regulation of ATP-binding cassette subfamily B member 1 by snail contributes to chemoresistance in colorectal cancer. Cancer Sci., 111, 84-97 (2020)

41) Gu X, Manautou JE. Regulation of hepatic ABCC transporters by xenobiotics and in disease states. Drug Metab. Rev., 42, 482-538 (2010)

42) Chen WJ, Wang H, Tang Y, Liu CL, Li HL, Li WT. Multidrug resistance in breast cancer cells during epithelial-mesenchymal transition is modulated by breast cancer resistant protein. Chin. J. Cancer, 29, 151-157 (2010).

43) Yin L, Castagnino P, Assoian RK. ABCG2 expression and side population abundance regulated by a transforming growth factor beta-directed epithelial-mesenchymal transition. Cancer Res., 68, 800-807 (2008).

44) Yano K, Tomono T, Ogihara T. Advances in studies of P-glycoprotein and its expression regulators. Biol. Pharm. Bull., 41, 11-19 (2018)

45) Yano K, Okabe C, Fujii K, Kato Y, Ogihara T. Regulation of breast cancer resistance protein and P-glycoprotein by ezrin, radixin and moesin in lung, intestinal and renal cancer cell lines. J. Pharm. Pharmacol., 72, 575-582 (2020).

46) Kamioka H, Tomono T, Fujita A, Onozato R, Iijima M, Tsuchida S, Arai T, Fujita Y, Zhang X, Yano K, Ogihara T. Moesin-mediated P-glycoprotein activation during snail-induced epithelial-mesenchymal transition in lung cancer cells. J. Pharm. Sci., 109, 2302-2308 
(2020).

47) Lan M, Kojima T, Murata M, Osanai M, Takano K, Chiba H, Sawada N. Phosphorylation of ezrin enhances microvillus length via a p38 MAP-kinase pathway in an immortalized mouse hepatic cell line. Exp. Cell Res., 312, 111-120 (2006).

48) Li YY, Zhou CX, Gao Y. Snail regulates the motility of oral cancer cells via RhoA/Cdc42/p-ERM pathway. Biochem. Biophys. Res. Commun., 452, 490-496 (2014).

49) Wang CC, Liau JY, Lu YS, Chen JW, Yao YT, Lien HC. Differential expression of moesin in breast cancers and its implication in epithelial-mesenchymal transition. Histopathology, 61, 78-87 (2012). 